\title{
O sujeito contemporâneo frente à produção de sentidos através dos filmes pornográficos como bens simbólicos
}

\author{
Júnior Ratts \\ Universidade Federal do Ceará - UFC \\ Hamilton Rodrigues Tabosa \\ Universidade Federal do Ceará - UFC
}

Resumo: Na relação entre Antropologia e audiovisual, compreende-se a imagem não somente como recurso de registro e descrição de situações, mas, sobretudo, como linguagem portadora de símbolos e significados que se contextualizam nas cenas mais diversas da pesquisa social. As imagens são caras à Antropologia porque nos permitem interpretar, compreender e produzir sentidos nos cotidianos onde estamos inseridos. Por isso, este trabalho tem por finalidade proporcionar reflexões sobre como os filmes pornográficos são constituídos em bens simbólicos e quais os impactos desse artefato da indústria da cultura de massas para o self, o corpo e a intimidade dos vários sujeitos que por ele são alcançados.

Palavras-chave: Cultura de massas; Bens simbólicos; Corpo; Mídia; Pornografia. 


\title{
El sujeto contemporáneo frente a la producción de significado a través de las películas pornográficas como bienes simbólicos
}

Resumen: La relación entre la antropología y audiovisual, entendemos que la imagen no sólo como un registro de situaciones que describen los recursos y, pero sobre todo como un portador lenguaje de símbolos y significados que están contextualizados en varias escenas de la investigación social. Las imágenes son importantes para la antropología, ya que nos permiten interpretar, comprender y producir sentidos en todos los días en los que operamos. Por lo tanto, este estudio tiene como objetivo proporcionar ideas sobre cómo las películas porno se hacen en bienes simbólicos y los impactos de estos artefactos de la industria de la cultura de masas para el auto, el cuerpo y la intimidad de los diversos temas que se logran por él.

Palabras clave: Cultura de masas; Bienes simbólicos; cuerpo; medios de Comunicación; Pornografía.

\section{The contemporary subject in front of the production of meaning through pornographic films as symbolic goods}

\begin{abstract}
In the relationship between Anthropology and audiovisual, we understand the image not only as a record of resource and describing situations, but above all as a language carrier of symbols and meanings that are contextualized in various scenes of social research. Images are expensive to Anthropology because they allow us to interpret, understand and produce senses in everyday where we operate. Therefore, this work has aims to reflect on how porn movies are made in symbolic goods and the impacts of this artifact of mass culture industry for the self, the body and the intimacy of the various subjects that are achieved by it.
\end{abstract}

Keywords: Mass Culture; Symbolic goods; body; media; Pornography. 


\section{Pensando o pornô como cinema}

A sexualidade tem sido um foco importante para a investigação antropológica e seus investigadores têm "rompido os tabus intelectuais erotofóbicos comuns em outras disciplinas mais tímidas" (VANCE, 2003: 07). De acordo com Almeida (2003: 03), o campo da sexualidade tem vindo a autonomizar-se na nossa sociedade e, por isso, "a sua abordagem em antropologia é necessariamente também um esforço de leitura, desconstrução e crítica das abordagens passadas do tema na disciplina". Ao compartilharmos deste ponto de vista, buscamos com este texto fugir da ideia da pornografia como um gênero cinematográfico menor e daí refletirmos sobre sua condição de bens simbólicos produtores de sentido para o sujeito contemporâneo que os consome, construindo hipóteses com base nas teses sobre corpo, imagem e pornografia desenvolvidas respectivamente por Le Breton, Baitello Jr., Sontag, dentre outros e outras autores, e também apoiando-nos nas falas de alguns atores e atriz apresentadas no documentário "The After Porns End" e contidas nas pesquisas que temos realizado com profissionais da indústria pornográfica.

Antes de prosseguirmos, é ainda preciso deixar claro que o material ao qual se refere este trabalho trata-se dos filmes que utilizam o sexo explícito (a exposição espetacular dos corpos e suas genitálias) como meio através do qual sua narrativa se desenvolve, independente da categoria e do público ao qual se destinam. Nestes termos, discutiremos as possíveis formas como os indivíduos veem e se relacionam com os filmes pornográficos (independente do gênero) e quais as consequências dessa relação para a identidade, o self, os corpos e a intimidade dos sujeitos alcançados pelas imagens-choque do pornô.

Para se cogitar/ponderar possíveis respostas, é preciso, a princípio, compreender que o pornô se enquadra naquilo que Giddens intitula como sistemas abstratos. De acordo com o sociólogo (1991: 115), "os sistemas abstratos propiciam uma boa dose de segurança na vida cotidiana que estava ausente nas ordens pré-modernas". Para o autor, o reconhecimento da importância dos mecanismos que constituem os sistemas abstratos se dá toda vez que alguém aciona qualquer tipo de tecnologia disponível no cotidiano, como um saque no banco ou o envio de uma carta. Ainda de acordo com Giddens (1991: 122, grifo nosso),

com o desenvolvimento dos sistemas abstratos, a confiança em princípios impessoais, bem como em outros anônimos, torna-se indispensável à existência social. A confiança impessoalizada deste tipo é discrepante da confiança básica. Há uma forte necessidade psicológica de achar outros em quem confiar, mas as conexões pessoais institucionalmente organizadas estão faltando em relação às situações sociais prémodernas. 
Ou seja, quando ligamos o reprodutor de DVD ou acessamos um vídeo pornô na internet, estamos, na verdade, procurando por esse outro em quem confiar, ainda que esse outro esteja envolvido em uma narrativa sexual explícita. Sendo assim, é no sexo do outro que estamos desejando restabelecer algum tipo de confiança perdida, algum elemento constituinte do self que se perdeu em meio ao "caos" pós-moderno. Nesse caso, o corpo midiatizado do pornô teria muito mais a nos oferecer do que conteúdo sensual/erótico com fins à excitação sexual? Possivelmente, mas para que cheguemos àquilo ao que o corpo pornorizado pode oferecer à confiança do sujeito e sua consequente construção do self, é necessário que, ao categorizarmos o filme pornô como parte dos sistemas abstratos, entendamo-lo como sendo, de fato, um filme, já que para o senso comum, do pornô fala-se filme, não se pensa filme.

Isso acontece por vários motivos, dentre eles pode-se citar, como exemplo, a "inexistência" ou a "existência conturbada" da tríade começo-meio-fim (característica primordial de qualquer gênero cinematográfico), a ausência da tridimensionalidade dos personagens (os personagens não possuem perfil psicológico ou dimensão social) e o rompimento com a convenção cinematográfica do olhar intradiegético ${ }^{1}$. Porém, ao nos afastarmos um pouco dessas características próprias do pornô que o constituem, por meio do senso comum, como um gênero cinematográfico menor, lembremo-nos que, apesar de todo aparente esvaziamento de personagens e enredo, o pornô se constitui como um produto que trabalha com a imagem em movimento que se sustenta sobre um eixo específico de começo-meio-fim, o qual Saéz (2003) vai chamar de "el circuito erección-penetración-eyaculación”.

Para além da organização fílmica proposta por Saéz, é importante, neste ponto, nos remetermos à tese sobre literatura pornográfica desenvolvida por Sontag (1967) quando argumenta sobre a desqualificação da pornografia como gênero literário em vista das proezas sexuais e do esvaziamento psicossocial dos personagens descritas nas obras e da paisagem irreal e a-histórica na qual os enredos decorrem. Apesar de teorizar sobre literatura, os argumentos de Sontag podem muito bem ser aplicados ao cinema. Diz ela sobre o gênero pornográfico e suas especificidades: "Tais negações do tempo social, do espaço e da personalidade reais, concretos e tridimensionais (assim como as ampliações 'fantásticas' da energia humana) são precisamente os ingredientes de um outro gênero de literatura, fundado num modo diverso de consciência" (SONTAG, 1967: 12). Levando a tese de Sontag para o cinema, podemos perceber o pornô como mais um dos vários gêneros cinematográficos existentes, o qual possui características próprias que não o diminuem frente aos outros gêneros, apenas o diferenciam.

${ }^{1} \mathrm{O}$ narrador intradiegético é o personagem que, dentro do texto, assume o papel de narrador. Apesar dessa técnica não ser comumente utilizada em filmes pornôs, há várias produções em que o personagem se apresenta como narrador do filme. 
Sendo assim, a compressão do filme pornô como filme nos leva a considerar as possibilidades de imersão do sujeito nas imagens pornográficas (que ocorre através dos processos de identificação e projeção) e principalmente, é claro, nas imagens dos corpos, visto que o corpo, nesse tipo específico de gênero, "é a fonte de comunicação, parecendo conter todos os discursos". (ABREU, 1996: 160). Dessa maneira, o jogo de olhares entre telespectador e personagens que caracteriza a construção da imagem cinematográfica, no pornô, terá o corpo como principal vetor. O corpo no pornô, pode-se dizer, é todo o olho do espectador; é feito do olhar do espectador que sobre ele se deixa construir ao construí-lo. Por isso, é esse olhar que pode conduzir o espectador a uma percepção nova ou renovada de sua condição, em especial, de sua condição erótica-sexual. Por isso, sempre que pensamos em como o pornô pode ser útil à constituição do self, lembramo-nos da seguinte fala de um dos entrevistados do

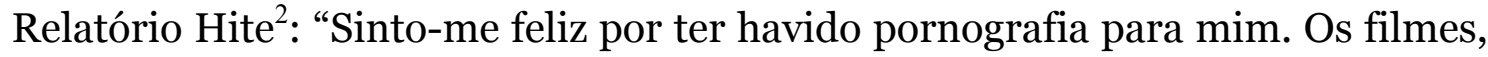
especialmente, mostraram-me que o sexo era mais do que eu havia aprendido e, apesar de ainda ter de lutar com várias inibições, muitas outras foram superadas em minha mente com a ajuda da pornografia” (HITE, 1986: 922).

Mas como o pornô adquire tamanha força a ponto de ajudar o sujeito em sua vida prática e subjetiva? Já vimos, no começo deste artigo, que o pornô se configura como um elemento pertencente aos sistemas abstratos por sua condição de filme e que, por isso, o outro e seu corpo envolvidos nas narrativas pornográficas adquirem uma capacidade de criar laços, por vezes mais fortes do que aqueles estabelecidos pelo sujeito em sua vida prática. Para entender melhor esse tipo de relação entre sujeito e imagem, é preciso recorrer à tese de Thompson (1998: 80) acerca da quase-interação mediada, a qual não tem o grau de reciprocidade interpessoal de outras formas de interação como a mediada ou a face a face, mas mesmo assim "cria um certo tipo de situação social na qual os indivíduos se ligam uns aos outros num processo de comunicação".

É, pois, no contexto da quase-interação mediada, que os corpos do pornô tornam-se/produzem bens simbólicos por duas principais condições, dentre outras: 1) Através dos discursos verbais e imagéticos que geram por meio de sua exposição espetacularizada, que subverte e reafirma ao mesmo tempo conceitos tradicionais sobre os gêneros e as sexualidades ${ }^{3}$; e 2) Por sua condição de elemento formador de um cenário erótico-sexual que se materializa na pele dos atores e que produz narrativas diversas apresentadas sob a forma de uma gramática sexual sobre o que é o sexual. Como se vê, o corpo no pornô constituise como cenário e narrativa para além da narrativa e do cenário nos quais são enquadrados. São então esses cenários-corpos, esses corpos-narrativas-que-

\footnotetext{
${ }^{2}$ A primeira pesquisa realizada por uma mulher sobre mulheres - é o resultado de uma série de inquéritos com garantia de anonimato das entrevistadas que envolve uma nova teorização do orgasmo feminino. Publicado pela primeira vez nos EUA em 1976, o impacto foi tal que o Relatório Hite é considerado um dos 100 livros fundamentais do século XX. A obra é editada em Portugal em 1978 e, recentemente, chegou à China, onde os manuais de Educação Sexual contêm transcrições e reproduções parciais sem autorização da autora.

${ }^{3}$ Por sua condição de produto cultural, a pornografia que liberta também reprime, pois como afirma Díaz-Benítez (2009: 594), o pornô "conserva e recria regras em um período que se acredita desregrado".
} 
narram que, compactados em signos, assumem o status de bens simbólicos responsáveis, sobretudo, pela produção de scripts sexuais que (organizados em histórias) "funcionam como guias de orientação ou de leitura, permitindo aos indivíduos situar-se e atribuir um sentido sexual às sensações, situações, palavras e estados corporais" (BOZON, 2004: 129). Assim, o corpo feito cenário e narrativa produz/reproduz o cenário narrativo ideal para essa leitura seguida de outras leituras e releituras para o indivíduo que "vive no meio da experiência sensível e que pode sobreviver apenas graças às sensações" (COCCIA, 2010: 9). É dessa maneira que o sujeito preso às sensações se vê, a um só tempo, asfixiado e vivificado pelas imagens sensacionais do sexo impactante, dos corpos expostos às mais variantes práticas que o esticam e o desmembram na produção de discursos que desempenham funções para além do simples estímulo sexual, como confirmou a fala do entrevistado de Hite.

Uma dessas funções é a de estranhar o corpo para então questionar os seus limites. Para compreender melhor essa proposição, é necessário responder brevemente a seguinte pergunta: o que é o corpo? De acordo com Le Breton (2003: 7), o corpo "é o eixo da relação com o mundo, o lugar e o tempo nos quais a existência toma forma através da fisionomia singular de um ator". Ainda segundo essa obra do sociólogo francês, essa fisionomia (que abarca todas as manifestações corporais do ator) só adquire sentido quando relacionadas ao conjunto de dados da simbologia própria do grupo social (idem: 9).

Assim sendo, se o corpo somente assume significado diante do outro, é porque ele deve, para sua sobrevivência em grupo, adaptar-se aos modelos de comportamento propostos pela sociedade e pela cultura através das várias formas de poder-saber. Por isso, aquilo que constrói o corpo não é somente a vontade do sujeito em ser corpo, mas sim este desejo combinado à "a materialidade do poder se exercendo sobre o próprio corpo dos indivíduos" (FOUCAULT, 1999: 146). Nesse contexto, o corpo parece, em um primeiro instante, só possuir uma forma de existir: adaptando-se aos discursos elaborados pela cultura e suprimindo-se/reprimindo-se em prol dessa mesma cultura. Em suma, "a socialização das manifestações corporais se faz sob os auspícios da repressão” (LE BRETON, 2012: 193). Assim, em prol de uma sociabilidade sem conturbações, o corpo se encolhe, se distancia do outro e se deixa ser apenas mais um em meio a uma realidade maquínica.

Mas não só de repressão vive o corpo contemporâneo. Há as ações que subvertem o ordenamento e a força do poder dos discursos sobre as corporalidades. E uma delas é a pornografia. Sim, a pornografia que, com seus excessos, faz ressurgir um corpo escondido pelo poder civilizatório ${ }^{4}$. Afinal, retomando Le Breton (2012: 197), "o uso físico de si culmina em uma jubilação, ele provoca o sentimento forte de existir", ainda que esses usos sejam, à luz da cultura, considerados amorais/anti-naturais/periféricos/marginais. Assim, quando Leite Jr. (2006: 235) faz uma análise sobre as imagens pornográficas

${ }^{4} \mathrm{O}$ pornô se configura como lugar "de ressignificação para mulheres e para outras minorias sexuais" (DÍAZ-BENÍTEZ, 2010: 119). 
sensacionalistas que envolvem secreções do organismo, o autor chega à conclusão de que "o que se espetaculariza nestas imagens é justamente o limite do "processo civilizador". Quer dizer, as imagens do pornô revelam, em sua essência, a possibilidade de transgredir as barreiras daquilo que é considerado normal e sadio e, com isso, oferece outras possibilidades de vivência aos corpos e, como consequência, outras verdades para o corpo.

Por isso, para Sontag (1967: 33), a imaginação pornográfica seria uma forma da imaginação humana que se projeta na arte e tem um "acesso peculiar a alguma verdade", seja essa verdade sobre o sexo, a sensibilidade ou o indivíduo. Segundo a autora, "aquele que transgride não apenas quebra uma norma. Ele vai a algum lugar onde os outros não vão; e conhece algo que eles não sabem" (idem: 33). Esse algo pode ser, dentre outras coisas, a capacidade que os corpos possuem de ir de encontro aos discursos do poder ao se afirmar por meio de sua corporeidade, ao assumir a completude de seu corpo e, obviamente, de seu self e identidade através da ação sexual. E talvez seja esse segredo escancarado por meio do corpo espetacular do pornô o que o espectador capta e traz para si a fim de repensar sua condição de sujeito que é obrigado/impelido a possuir um corpo social e um corpo que é seu. O filme pornô não somente revela a existência desses dois corpos, mas, pelo contrário, confirma que mais corpos são possíveis de existir distante, ainda que pouco ou não, dos discursos normatizadores do processo civilizatório. Em suma, os signos em excesso do sexo são transformados em bens simbólicos que possibilitam ao sujeito humanizar-se justamente pelo reconhecimento de seu corpo como um corposexual, como um objeto aberto aos desígnios das pluralidades subjetivas. Ou seja, o que o filme pornográfico (e a pornografia) faz é "estabelecer uma cunha entre a existência de uma pessoa enquanto ser humano completo e sua existência como entidade sexual, enquanto na vida comum uma pessoa 'saudável' é aquela que impede que tal lacuna se amplie". (SONTAG, 1967 apud ABREU, 1996: 126).

Desta maneira, o pornô, geralmente considerado pouco humano, é responsável tanto por estimular sexualmente os sujeitos que o consomem como por humanizá-los. E como falamos no despertar de corpos que a pornografia proporciona, pode-se pensar que, em último caso, ela humaniza justamente por despertar as transcorporalidades ${ }^{5}$ dos indivíduos que a devoram com o olhar e que, por meio desse olhar devorador, são constituídos. Assim, o sujeito se multiplica e se unifica através e na pornografia, mesmo que no campo da imagem e do imaginário (do simbólico), mesmo que no tempo da imagem de uma penetração ou de um gozo. Dessa forma, a pornografia, por meio das imagens performativas do outro que pratica a ação sexual, incentiva a liberdade corporal daquele que se compraz com as imagens do pornô e que nelas se

\footnotetext{
${ }^{5} \mathrm{O}$ conceito de transcorporalidades se destaca como "categoria crítica capaz de agregar diferentes possibilidades para pensarmos as manifestações do corpo contemporâneo. Seja na publicidade, na mídia, na arte ou no cotidiano, essas transcorporalidades surgem como estados de performance, em que o corpo ressalta suas nuanças poéticas, plásticas, que evidenciam a discursividade visual estratégica. Nesse sentido, o corpo emerge sempre em trânsito - deslocamento constante e que aponta o movimento estratégico corporal". (GARCIA, 2005: 13).
} 
projeta, visto que "o corpo tornou-se a prótese de um eu eternamente em busca de uma encarnação provisória para garantir um vestígio significativo de si” (LE BRETON, 2003, p. 29). Sendo assim, a pornografia, por conta de suas emoções e pulsões efêmeras e por vezes desconexas com a realidade, produz esses momentos provisórios de êxtase e de construção do Si Mesmo.

\section{O pornô e as imagens-choque}

Mas qual o contrário desse projetar-se/multiplicar-se corporal na e por meio da pornografia tendo em vista sua condição de artefato da cultura de massas produtor de bens simbólicos? Afinal, como pensar que um produto que trabalha geralmente e, sobretudo, com estereótipos sexuais acerca dos gêneros e das sexualidades possa permitir uma forma de libertação física e subjetiva? De início, é preciso compreender que as imagens estereotipadas seguem as condições impostas pelo imaginário na formação de scripts sexuais que, por serem concebidos a partir das expectativas sobre o sexo forjadas pela cultura, são absorvidos "mais naturalmente" como guias de orientação sexual ${ }^{6}$.

Em segundo, não podemos esquecer que o processo de construção do self por meio da imagem do pornô se dá no contexto das emoções em excesso que caracterizam as formas de ser e estar na Contemporaneidade. Sendo assim, de acordo com Lacroix (2006), as imagens dos corpos-pornôs podem ser caracterizados como imagens-choque ${ }^{7}$, as quais preenchem a paisagem atual cuja emoção, de uma forma geral, foi instrumentalizada e a sensibilidade tornou-se dependente da técnica (neste caso, técnica em trabalhar com perfeição na formulação de tipologias sobre os corpos, os gêneros, as sexualidades e as etnias, etc). Para Lacroix, esse processo culmina na nova doença do século, visto que "o culto da emoção-choque substitui o excesso da sensibilidade pela sensibilidade dos excessos”. (2006: 147).

Assim, a produção, a reprodução e o consumo das imagens de corpos em seus extremos na pornografia conduzem a um caminho apontado por Baitello (2005): a iconofagia. Quer dizer, o sujeito persuadido/estimulado a consumir as imagens erótico-sexuais como se delas não pudesse fugir e como se precisasse acessá-las a todo instante em sua vida sexual, acaba por ele mesmo a tornar-se uma espécie de extensão da imagem que vê e, por conseguinte, a própria imagem. O prazer instrumentaliza-se e o sexo cotidiano "obriga-se" a obedecer um conjunto de regras a fim de produzir imagens-choque da própria intimidade. Imagens de si para si que se alimentam das (e alimentam as)

\footnotetext{
${ }^{6}$ Diz Bozon (2004: 129): "Parece que nada de sexual poderia acontecer, sequer uma masturbação solitária, se não existissem produções sociais e mentais, assumindo a forma de cenários, em que atos, relações e significados da sexualidade se encontrem inscritos e organizados em histórias. Esses cenários funcionam como guias de orientação ou de leitura, permitindo aos indivíduos situar-se e atribuir um sentido sexual às sensações, situações, palavras e estados corporais".

7 “O excesso e a ênfase, o exagero e a reiteração são fundamentais à economia do objeto na expressão pornô". (ABREU, 1996: 130).
} 
imagens excessivas do sexo e se, de alguma forma, normatizam a sexualidade dos sujeitos, também servem como mecanismos de auto-descoberta sexual. Como percebemos em uma entrevista realizada com o ator de filmes pornôs gays Wagner Vittoria: "O pornô te estimula a provar coisas novas, posições diferentes, diferentes coisas para aquecer o sexo. Tudo que faço na cama aprendi assistindo filmes pornôs e acredito que com quase todos é assim”. Já o ator brasileiro Andy Star, que atua há alguns anos na indústria pornô gay nacional, afirma que "a emoção de fazer algo diferente" é uma das principais consequências positivas de fazer parte das redes do pornô. Dessa maneira, a emoção não é simples instrumento de mecanização dos corpos e dos desejos, mas também se constitui como ferramenta tática de revitalização, experimentação e, em casos extremos, de sobrevivência do Eu erótico-sexual.

Assim, o sujeito vestido de mídia enxerga-se então nela (na mídia) e fora dela por conta de uma característica muito peculiar apontada por MerleauPonty (2002): a capacidade do indivíduo humano em ser vidente e visível ${ }^{8}$. Capacidade que é superlativada graças ao acesso a um turbilhão de imagens que, segundo Baitello (2005), não são consumidas por sua "função janela", mas por sua "função biombo". Quer dizer, ao invés de remeter ao mundo e às coisas, as imagens passam a bloquear o acesso do indivíduo às reais coisas da vida cotidiana, remetendo-o apenas ao repertório ou repositório das próprias imagens. Daí que "na cultura de massa, o fato já não é mais um elemento do mundo natural, o que parece como fato é o estereótipo: aquilo que todo mundo vê, que todo mundo consome" (BARTHES, 1990: 184-5).

Por tudo isso, o fenômeno da imagem-choque associado aos conteúdosestereótipos da cultura de massa gera a necessidade do corpo-pornô em assumir a condição de corpo-máquina que, em sua condição de imagem-biombo, responsabiliza-se pela produção de si, dentro de padrões normativos, para então produzir outros corpos. O que implica que, ao assumir um repertório de gestos e manifestações sexuais tradicionalmente espetaculares, o corpo pornorizado nunca possa "mostrar-se frágil, já que é programado para a produção e para a produtividade" (ABREU, 1996: 61). Paradoxalmente, este mesmo corpo que limita a visão e o comportamento dos sujeitos envolvidos por ele em relação ao mundo, expande esse mesmo olhar sobre o Si Mesmo, revelando que estas imagens possuem também a dimensão de imagem-janela (pois as performances sexuais midiatizadas no conduzem a pensar sobre as condições reais do sexual e do erótico na Contemporaneidade). Dessa maneira, os indivíduos de ambos os lados da tela - envolvidos pelas imagens de impacto dos corpos em suas narrativas sexuais - sofrem as consequências de precisarem se tornar, em suas performances, o sensation-seeker ou o buscador de sensações, o qual, nas palavras de Lacroix (2006: 19), "é o herói de nosso tempo". Isso, a um som tempo, limita e expande as potencialidades físicas e subjetivas do corpo (dentro

\footnotetext{
${ }^{8}$ Diz Merleau-Ponty (2002: 20-21): "O enigma consiste em que o meu corpo é ao mesmo tempo vidente e visível. Ele, que mira todas as coisas, pode também olhar-se, e reconhecer então naquilo que vê o 'outro lado' do seu poder vidente. Ele vê-se vendo, toca-se tocando, é visível e sensível para si mesmo".
} 
e fora da tela), pois descontrói e reconstrói seus contornos em conformidade com um desejo que em sua materialidade estereotipada constrói ou não chances para a realização pessoal. Assim, a conformidade a uma gramática do desejo é capaz de produzir, ainda que dentro de regras normativas, um corpo heroico ${ }^{9}$. Essa é uma boa explicação para o porquê da produção em escala de pornografia se dar em conformidade com uma série de publicações não pornográficas e "especializadas" em tornar a vida sexual do homem comum mais intensa e emocionante (em especial as revistas de variedades).

No final das contas, ambos os corpos (o corpo-pornô e o corpo que consome o corpo-pornô) se alimentam do imaginário cultural de que a felicidade sexual somente pode ser alcançada em seus extremos e extravagâncias e que a conformação desta conquista está na construção e/ou na busca das imagens de corpos em êxtase. Resumidamente, "corpos nascem de outros corpos e se alimentam de outros corpos” (BAITELLO, 2005: 93). De forma, paradoxalmente, normativa (quando é o caso) e prazerosa.

\section{Conclusão - O jogo do social}

Chegamos ao final deste trabalho perguntando-nos onde estará a brecha que nos permite respirar em paz, que nos livra do peso que o processo civilizador deposita sobre nossos corpos ${ }^{10}$. Isso porque, como vimos, ambos os corpos - o corpo-telespectador e o corpo-pornô - alimentam-se um do outro num círculo vicioso em que fica impossível afirmar quem gera quem. A esta conclusão (odiamos essa palavra!) resta-nos sempre pensar na cultura, nas formas como ela age a partir dos artefatos humanos para normatizar os corpos, fisicamente e subjetivamente e como os sujeitos interagem com estes mesmos artefatos a favor de si mesmos (por vezes, se deixando normatizar em prol de uma aparente libertação).

De acordo com Foucault (1999), a partir do momento em que o poder exerce seus investimentos sobre os corpos, como consequência direta de suas conquistas, emerge inevitavelmente a reivindicação do corpo sobrepujado contra o poder. Dentre estas formas de revelia, Foucault cita o prazer como uma ferramenta a ser usada contra as normas morais da sexualidade, do casamento e do pudor.

Em contrapartida (e ainda de acordo com Foucault), o poder se apropria dos discursos e ações transgressivos para continuar se manifestando. Diz ele: “Como resposta à revolta do corpo, encontramos um novo investimento que não

\footnotetext{
${ }^{9}$ Neste sentido e partindo da tese de Geertz (2001: 183) de que "as palavras, imagens, gestos, marcas corporais e terminologias [...] não são meros veículos de sentimentos alojados noutro lugar, como um punhado de reflexos, sintomas e transpirações. São o locus e a maquinaria da coisa em si”, podemos chegar à hipótese de que os estímulos produzidos pelo pornô, por meio dos discursos imagéticos e verbais, em atores e telespectadores são ferramentas indispensáveis à materialização de seus corpos e desejos.

${ }^{10}$ Apesar de um aparente descontentamento com essa relação corpo-mídia, vale lembrar que somos responsáveis pela construção do nosso eu à medida que as instituições de ordem primárias perdem seu poder e que, por isso "tornamo-nos responsáveis pelo desenho de nossos próprios corpos, e em certo sentido [...] somos forçados a fazê-lo quanto mais póstradicionais forem os contextos sociais em que vivemos" (GIDDENS, 2002: 98). Em outras palavras, "os conteúdos da subjetividade dependem, cada vez mais, de uma infinidade de sistemas maquínicos”. (GUATARRI, 1993:177).
} 
tem mais a forma de controle-repressão, mas de controle-estimulação" (1999: 147). Com base nessa afirmação, o pornô poderia continuar a gerar e exibir imagens estimulantes e espetaculares dos corpos, mas os corpos no pornô precisariam de fato ser estimulantes e espetaculares. Ou seja, não há uma guerra do corpo contra o poder exatamente, mas uma roda-viva no qual o poder investe estrategicamente sobre um corpo tático que se rebela ou se compraz dentro de suas limitações de consumidor-produtor nato de bens simbólicos. Isso nos faz lembrar de outra tese de Foucault (1997), segundo a qual o rompimento da verdade se dá sempre dentro de uma "exterioridade selvagem”. Quer dizer, "não nos encontramos no verdadeiro senão obedecendo às regras de uma 'polícia' discursiva que devemos reativar em cada um dos nossos discursos". Assim, a sociedade disponibiliza de materiais que, mesmo em seu estado de legi-signos ${ }^{11}$, possibilitam um fazer por si mesmo $^{12}$, fenômeno social que marca a constituição física e identitária do indivíduo contemporâneo. Sob esse ponto de vista, o pornô, em sua normatização e subversão, oferece um espaço de constituição do Si Mesmo, conforme revela a fala de Asia Carrera, ex-atriz pornô estadunidense, registrada no documentário "The after porns end":

Eu saía com meus amigos esquisitos e eles tinham revistas pornôs e olhavam para elas e eu olhava por cima de seus ombros pensando: "Queria que me olhassem desse jeito”. Era a fantasia mais extravagante que alguém me achasse bonita e sexy. Toda a vida eu fui a CDF. Era um desejo se tornando realidade o fato de alguém querer me ver numa capa de revista. Quando comecei no pornô, eu pensei: "Posso escolher com qual desses lindos rapazes transar e vocês vão me pagar por isso, me colocar em uma capa e me dar uma tonelada de dinheiro?”. Era um progresso muito grande vindo de onde eu vim.

Ou seja, as recuperações do corpo pela pornografia e a tomada da pornografia pelo poder para novos investimentos sobre o corpo fazem parte do desenvolvimento estratégico da luta, cuja indefinição é preciso ser aceita (FOUCAULT, 1999: 146-7). A brecha está então no jogo do social ${ }^{13}$ em que joga a sociedade com suas imagens corporais carregadas de sensações e tradicionalismos e o sujeito que consome estas imagens de diferentes formas, resultando em diferentes paisagens de vida e consumo. A brecha está, assim, na indefinição e também no reconhecimento de que os corpos do pornô podem nos apresentar uma outra realidade que intervenha em nosso self e identidade e que esta realidade pode ser estrategicamente construída pelo poder para a satisfação de uma audiência a ser estimulada e/ou manipulada pelas imagens nas quais taticamente se projeta para fazer gozar o corpo em uma performance pessoal estimulada pela projeção em imagens cujas as aparentes materializações erótico-sexuais em consonância com o imaginário, são na verdade um grande jogo de sensações que se apropriam de maneira performaticamente subversiva deste mesmo imaginário.

\footnotetext{
${ }^{11}$ De acordo com Santaella, uma das categorias fenomenológicas que regem os signos é seu caráter de lei. Assim, a ação da lei e, por consequência, do legi-signo é "operar tão logo encontre um caso singular sobre o qual agir. A ação da lei é fazer com que o singular se conforme, se molde à sua generalidade. É fazer com que, surgindo uma determinada situação, as coisas ocorram com aquilo que a lei prescreve.” (SANTAELLA, 2004, p. 13).

${ }^{12}$ Segundo Bauman (2008: 76 e 77), “'tornar-se' apenas, como conseqüência do acidente de ser concebido e nascer de uma mãe, não será o suficiente [...] "Fazer de si mesmo uma mercadoria vendável" é um trabalho do tipo faça-vocêmesmo e um dever individual. Observemos: fazer de si mesmo, não apenas tornar-se, o desafio e a tarefa a ser cumprida".

${ }^{13}$ Sempre que falo em jogo, recordo-me da tese de Simmel, segundo a qual “(...) não somente joga na sociedade aquele que a mantém externamente, mas com ele 'joga-se' de fato a "sociedade”. (SIMMEL, 2006: 72).
} 


\section{REFERÊNCIAS}

ABREU, Nuno Cesar. O olhar pornô: A representação do obsceno no cinema e no vídeo. Campinas, Mercado de Letras, 1996.

ALMEIDA, Miguel Vale de. Antropologia e Sexualidade: consensos e conflitos teóricos em perspectiva histórica. In: FONSECA, Lígia; SOARES, C.; VAZ, J.M. (orgs). A Sexologia: perspectiva multidisciplinar. Coimbra: Quarteto, vol. 2, 2003.

BAUMAN, Zygmunt. Vida para consumo. Rio de Janeiro: Jorge Zahar Ed., 2008.

BOZON, Michel. Sociologia da sexualidade. Rio de Janeiro, Ed. FGV, 2004.

COCCIA, Emanuele. A vida sensível. Florianópolis: Cultura e Barbárie, 2010.

DÍAZ-BENÍTEZ, María Elvira. Retratos de uma orgia: a efervescência do sexo no pornô. In: DÍAZ-BENÍTEZ, María Elvira \& FÍGARI, Carlos Eduardo (Org.). Prazeres dissidentes. Rio de Janeiro: Garamond, 2009.

FOUCAULT, Michel. A ordem do discurso. Lisboa, Relógio D’Água Editores, 1997.

Microfísica do poder. Rio de Janeiro: Graal, 1999.

GARCIA, Wilton. Corpo, mídia e representações: estudos contemporâneos. São Paulo, Pioneira Thompson Learning, 2005.

GIDDENS, Anthony. As conseqüências da modernidade. São Paulo: UNESP, 1991. . Modernidade e identidade. Rio de Janeiro: Jorge Zahar Ed.,

2002.

GUATARRI, Félix. Da produção da subjetividade. In: PARENTE, Andre. Imagem Máquina: a era das tecnologias do virtual. Rio de Janeiro: Ed. 34, 1993.

GEERTZ, Clifford. O Saber Local: novos ensaios em antropologia interpretativa. Petrópolis: Editora Vozes, 1997.

HITE, Shere. O relatório Hite sobre a sexualidade masculina. São Paulo, Ed.Difusão Européia do Livro, 1986.

LACROIX, Michel. O culto da emoção. Rio de Janeiro: José Olympio, 2006.

LE BRETON, David. Adeus ao corpo: antropologia e sociedade. Campinas: Papirus, 2003.

A sociologia do corpo. 2. ed. Petrópolis, Editora Vozes, 2007. Antropologia do corpo e modernidade. Petrópolis, Editora

Vozes, 2012.

LEITE, Jorge Jr. Das Maravilhas e Prodígios sexuais: a pornografia "bizarra" como entretenimento. São Paulo: Annablume, 2006.

MERLEAU-PONTY, Maurice. O olho e o espírito. Lisboa: Vega, 2002.

MORIN, Edgar. Cultura de Massas no Século XX: O Espírito do Tempo. Rio de Janeiro, Forense, 1967.

SAEZ, Javier. El macho vulnerable: pornografia y sadomasoquismo. 2003. Disponível em: <http://www.hartza.com/fist.htm>.

SANTAELLA, Lucia. Semiótica aplicada. São Paulo: Pioneira Thomson Learning, 2004.

SIMMEL, Georg. Questões fundamentais da sociologia. Rio de Janeiro: Jorge Zahar Editor, 2006. 
SONTAG, Susan. A imaginação pornográfica. In: A vontade radical. Rio de Janeiro: Cia. das Letras, 1987.

THOMPSON, John B. A mídia e a modernidade: uma teoria social da mídia. Petrópolis: Vozes, 1998.

VANCE, Carole S. A Antropologia redescobre a sexualidade: um comentário teórico. In: FONSECA, Lígia; SOARES, C.; VAZ, J.M. (orgs). A Sexologia: perspectiva multidisciplinar. Coimbra: Quarteto, vol. 2, 2003. 